\title{
Active volatiles of cabernet sauvignon wine from Changli County
}

\author{
Yong-Sheng Tao, Hua $\mathrm{Li}^{*}$ \\ College of Enology, Northwest A \& F University, Yangling, Shaanxi, China; Corresponding author: lihuawine@nwsuaf.edu.cn
}

Received 6 September 2009; revised 27 September 2009; accepted 28 September 2009.

\begin{abstract}
This study investigated the contribution of volatile compounds to the overall aroma of Cabernet Sauvignon wines from Changli County (China). Wine samples were collected from vintages from 2000 to 2005. Volatile compounds were extracted by PDMS solid-phase micro-extraction fibers and identified by Gas Chromatography-Mass Spectrometry (GC-MS). A total of 65 volatile compounds were identified and quantified, including higher alcohols, ethyl and acetate esters, and fatty acids. According to their odor active values (OA-Vs), 21 volatile compounds were considered to be the powerful impact odorants of Cabernet Sauvignon wines from Changli. Odor descriptions of impact volatiles suggested Cabernet Sauvignon red wines from Changli County as having a complex aroma, which included not only pleasant floral and fruity odors, but also cheese, clove flavors, and grassy and smoky aromas.
\end{abstract}

Keywords: Cabernet Sauvignon; Red wine; Aroma compounds; OAV; GC-MS

\section{INTRODUCTION}

Cabernet Sauvignon, Cabernet Franc and Cabernet Gernischet are known as "the Three Pearls" of wine grapes in China, often used by Chinese wineries to produce premium quality red wines. In contrast to Cabernet Franc and Cabernet Gernischet, Cabernet Sauvignon can be found in almost all wine production districts and has the largest growing area in China. Changli County, a region of North China, has become a famous wine producing district as one of the four districts of Wine Denomination of Origin in China, and the winemaking sector is the principal economy of the county. In Changli County, the main red grape variety used in wine production is Cabernet Sauvignon. The growing area of Cabernet Sauvignon is 2400 $\mathrm{Ha}$ and accounts for $72 \%$ of the total grape planting areas.
Therefore, it is important to understand the characters of Cabernet Sauvignon red wine made from Changli.

Wine aroma is an important aspect of wine quality. In a recent consumer study, the flavor of wine was found to be one of the attributes most important to consumers when buying wine. Volatile compounds influence the organoleptic characteristics of wines, particularly the aromatic characteristics, and the aroma constituents of different grapes and wines have been extensively studied in the last few years. In the order of 1000 volatile compounds, such as alcohols, esters, organic acids, phenols, thiols, monoterpenes and norisoprenoids have been found in wines, only several tens of which can be impact odorants. Volatile compounds found in wines can reflect the influence of variety, climate and soil, etc. Therefore, these compounds play a decisive role in wine quality and regional characteristics [1-3]. Since the contribution of volatile compounds to the final aroma depends on whether the concentration in the wine is above the perception threshold, OAV (odor activity value) was introduced to determine impact odorants $[4,5]$. OAV calculation depends both on measuring concentration and on odor threshold in the same matrix. Only those odorants with OAV $>1$ can be perceived.

Some studies have indicated that the young red wines of Cabernet Sauvignon, Merlot and Grenache have similar aromatic characteristics [6]. The most active odorants of these three varietal young red wines suggested by aroma extract dilution analysis (AEDA) were isopentyl and $\beta$-phenylethyl alcohols, the ethyl esters of butyric, isobutyric, 2-methyl butyric and hexanoic acids, $\gamma$-nonalactone and eugenol. Data showed that differences between these varieties are quantitative rather than qualitative $[7,8]$. In past decades, the unique characteristics of Chinese wine began to attract notice with the rapid development of wine production in China. However, sensory data for Chinese wine are scarce, especially for wines with denomination of origin. A study of aromatic compounds of the Cabernet Sauvignon red wine Shacheng (China) showed that ethyl octanoate, ethyl hexanoate and isopentyl acetate jointly contributed to more than $97 \%$ of the global aroma according to OAVs [9]. 
However, this result may be misleading; further studies are necessary to understand the nature of aromatic compounds found in premium Chinese wine.

Quantitative assessment of volatile compounds in wines has met with some difficulty, mainly due to their complexity and large concentration variations from $1 \mathrm{ng} / \mathrm{L}$ to several $\mathrm{g} / \mathrm{L}$. Therefore, sample preparation essentially consists of extraction and concentration of the compounds of interest. In this study, volatile compounds were extracted by solid-phase micro-extraction and detected by GC-MS, which has been published [10]. This work reported the results of the first study profiling of the major volatile compounds and the impact odorants in Cabernet Sauvignon wines from the Changli County region of China.

\section{MATERIALS AND METHODS}

\subsection{Wines}

Changli Cabernet Sauvignon wines from vintages between 2000 and 2005 (Each year has two samples which were supplied by Huaxia Winemaking Company and Yueqiannian Winemaking Company respectively, Changli County.) were used to analyze the composition of volatile compounds. Wine samples were collected six months after winemaking and then stored at 5-10 ${ }^{\circ} \mathrm{C}$ before analysis.

Wine making: Sound grapes of Cabernet Sauvignon were obtained from the vineyard. Grapes were destemmed and crushed on a commercial grape destemmer-crusher, the output of which was pumped to stainless steel tanks. The must was treated with sulfur dioxide $(45 \mathrm{mg} / \mathrm{L})$ and soaked for approximately $24 \mathrm{~h}$. Alcohol fermentation was going on at $25-30^{\circ} \mathrm{C}$. After fermentation, the wines were racked and subjected to malo-lactic fermentation. The wines were then racked and sulfur dioxide $(75 \mathrm{mg} / \mathrm{L})$ was added. The wines were stored at $15^{\circ} \mathrm{C}$ in stainless-steel tanks. Racking and stabilizing processes were carried out prior to analysis.

Reducing sugars, density, ethanol, extract, titratable acidity, $\mathrm{pH}$, volatile acidity, total and free $\mathrm{SO}_{2}$ were analyzed with the methods provided by the Office International de la Vigne et du Vin (OIV, 1990) [11].

\subsection{Reagents}

All reagents used were analytical grade. Absolute ethanol, tartaric acid, and sodium chloride were purchased from Xi'an chemical factory (Xi'an, China). Water was obtained from a Milli-Q purification system (Millipore). Solvents did not require additional distillation. 32 pure reference compounds were from Sigma-Aldrich (China sector): ethyl acetate, ethyl butyrate, 1-propanol, 2-methyl thiophene, 2-methyl-1-propanol, isopentyl acetate, 1-butanol, 2,5-dimethyl-tetrahydro-furan, isopentyl alcohol, ethyl hexanoate, ethenyl benzene, ethyl lactate, 1-hexanol, 3octanol, ethyl octanoate, furfural, decanal, cis-geraniol, $\beta$ ionone, linalool, $\beta$-damascenone, ethyl decanoate, phenethyl acetate, 1-decanol, hexanoic acid, benzyl alcohol, 2phenyl-ethanol, ethyl dodecanoate, ethyl hexadecanoate, octanoic acid, decanoic acid, and p-ethyl-phenol.

\subsection{Standard Solutions}

Exact volumes of the standard chemical compounds were dissolved in synthetic wines to prepare the calibration data. These standard compounds were dissolved in synthetic wines at concentrations three orders of magnitude higher than typically found in wines. For quantification, five-point calibration curves were prepared for each compound using the method described by Ferreira et al. (2000) [8]. The final alcohol content of the synthetic wine was $11 \%(\mathrm{v} / \mathrm{v})$. The synthetic wine had $6 \mathrm{~g} / \mathrm{L}$ of tartaric acid and its $\mathrm{pH}$ was 3.3-3.4 adjusted with $1 \mathrm{M} \mathrm{NaOH}$ (synthetic wine matrix). Octan-3-ol was employed as an internal standard because it was not the typical volatile compound in wine and it had a perfect ion peak shape and peak place in the TIC. Exact volumes of octan-3-ol were dissolved in absolute ethanol. All these solutions were stored at $4{ }^{\circ} \mathrm{C}$ in darkness $[1,12]$.

\subsection{Solid Phase Micro-Extraction (SPME) Sampling Conditions}

SPME was performed following the methods described previously [13]. Both wine samples and model solutions were analyzed in 15-ml glass vials, filled with $10 \mathrm{ml}$ of each sample and $2 \mathrm{~g} \mathrm{NaCl}$. For SPME analyses, the vials were dipped in a thermostatic water bath. A magnetic stirring bar was placed in the vial to agitate the sample. PDMS (100 $\mu \mathrm{m}$ Polydimethylsiloxane) was used as the solid-phase fiber for micro-extraction. The vial was equilibrated at $40^{\circ} \mathrm{C}$ for $10 \mathrm{~min}$, and the power magnetic stirrer was then added. SPME was performed at $40^{\circ} \mathrm{C}$ for $30 \mathrm{~min}$, and was immediately followed by the desorption of the analytes into the gas chromatograph injector. The solid-phase fiber remained into the injector for about 3 $\min$.

\subsection{GC-MS Analysis}

GC-MS apparatus: TRACE DSQ (Thermo-Finnigan, USA). Analytical column: DB-Wax capillary column $(30 \mathrm{~m} \times 0.32 \mathrm{~mm}$ i.d., $0.25 \mu \mathrm{m}$ film thickness), (J\&W, Folsom, USA). Carrier: He at $1 \mathrm{ml} / \mathrm{min}$. The temperature program used was $40{ }^{\circ} \mathrm{C}$ for $3 \mathrm{~min}$, raised to $160{ }^{\circ} \mathrm{C}$ at 4 ${ }^{\circ} \mathrm{C} / \mathrm{min}$, then raised to $230^{\circ} \mathrm{C}$ at $7{ }^{\circ} \mathrm{C} / \mathrm{min}$ for $8 \mathrm{~min}$. The transfer line temperature was $230^{\circ} \mathrm{C}$, and the injection temperature was $250{ }^{\circ} \mathrm{C}$. Mass spectra were recorded in electron impact (EI) ionization mode. Mass spectrometry: 
Table 1. General composition of cabernet sauvignon must and wine.

\begin{tabular}{cc}
\hline & Ranges \\
\hline Must composition & \\
Titratable acidity $(\mathrm{g} / \mathrm{L})$ & $9.3-9.7$ \\
$\mathrm{pH}$ & $3.2-3.4$ \\
Reducing sugars $(\mathrm{g} / \mathrm{L})$ & $191-200$ \\
Wine composition & \\
Density $\left(20^{\circ} \mathrm{C}\right)$ & $0.991-0.994$ \\
Ethanol $(\%, \mathrm{v} / \mathrm{v})$ & $10.4-12.1$ \\
Reducing sugars $(\mathrm{g} / \mathrm{L})$ & $0.78-1.82$ \\
Extract $(\mathrm{g} / \mathrm{L})$ & $21-25$ \\
Titratable acidity $(\mathrm{g} / \mathrm{L})$ & $3.6-4.5$ \\
$\mathrm{pH}$ & $3.3-3.6$ \\
Volatile $^{\mathrm{a}} \mathrm{acidity}(\mathrm{g} / \mathrm{L})$ & $0.46-0.71$ \\
$\mathrm{Free}_{2} \mathrm{SO}_{2}(\mathrm{mg} / \mathrm{L})$ & $11-19$ \\
Total $_{\mathrm{SO}}(\mathrm{mg} / \mathrm{L})$ & $90-121$ \\
\hline
\end{tabular}

(a) As tartaric acid. (b) As acetic acid.

mass range 33-450 amu, scanned at $1 \mathrm{~s}$ intervals. The ion source temperature was $230^{\circ} \mathrm{C}$.

\subsection{Qualitative Analysis and Quantification}

Identification of volatile compound was achieved by comparing mass spectra obtained from the sample with those from pure standards injected in the same conditions, and by comparing the Kov'ats index or the mass spectra found in the NIST2.0 MS library Database or found in the literature.

An internal standard quantification method using octan-3-ol was employed. Quantitative data of the identified compounds were obtained by interpolation of the relative areas versus the internal standard area using calibration graphs built for pure reference compounds. The concentration of volatile compounds, for which there was no pure reference, was obtained by using the same calibration graphs as the compounds with the most similar chemical structure according to the formula and chemical character $[3,14]$.

\section{RESULTS AND DISCUSSION}

Those general compositions of sample wines were displayed in Table 1. There is no significant difference among these samples.

Volatile compounds found in Cabernet Sauvignon red wines from Changli County detected by SPME-GC-MS are shown in Table 2. There are 65 aroma compounds and their concentrations vary from $0.5 \mu \mathrm{g} / \mathrm{L}$ to $2.23 \mathrm{~g} / \mathrm{L}$. The majority of the compounds were higher alcohols, esters, and fatty acids. Other compounds identified were terpenes, norisoprenoids, volatile phenols and furans. The $\mathrm{OAV}$ of each compound was obtained using concentration divided by odor threshold. Twenty-one compounds had OAV values greater than one. Impact odorants of the
Chardonnay white wine from Changli had previously been identified using the same method. Thirteen of the 41 volatile compounds detected had aroma activity and contributed to the pleasant fruity and floral aroma of the Chardonnay wine [14]. The active aroma compounds identified in that study were approximately half of the total volatiles detected in Cabernet Sauvignon red wines identified in this study, indicating the aroma of the red wine may be more complex.

\subsection{Esters}

Esters found in wine include acetates, ethyl esters and other esters of fusels and fatty acids. In the sample wines, 21 esters were identified with concentrations ranging from 62 to $390 \mathrm{mg} / \mathrm{L}$. Contents of esters accounted for about $20-30 \%$ of the total aroma compounds. Five acetates, 13 ethyl esters and three others were found in this chemical group. In acetates, the OAVs of ethyl acetate and isopentyl acetate were higher than one. Ethyl acetate may contribute a pleasant, fruity fragrance to the general wine aroma at concentrations lower than $150 \mathrm{mg} / \mathrm{L}$. However, at higher concentrations, ethyl acetate can contribute a sour-vinegar odor [21]. Isopentyl acetate contributes a fresh fruity odor, reminiscent of banana flavors.

Among 13 ethyl esters, ethyl butyrate, ethyl isovalerate, ethyl hexanoate, ethyl lactate and ethyl octanoate have OAVs over one. Ethyl butyrate has the favor of sour fruit, strawberry and sweet fruit. Ethyl isovalerate smells of banana and sweet fruit. Ethyl hexanoate has the flavor of green apple, fruit, strawberry and anise. Ethyl octanoate gives pineapple, pear and floral aromas. Ethyl lactate contributes lactic and raspberry odors. These active ethyl esters are responsible for the full-bodied fruity and floral aroma of wine. Results also confirmed most of the wines rich in these compounds showed elevated levels of higher alcohol acetates, thus adding to the sweet and soapy odors, and pleasant floral and fruity aroma.

Esters of fusel and fatty acids had lower concentrations, but their odor thresholds were also lower. In this study, isopentyl lactate had OAVs over one, and influences the overall aroma of the wine. Isopentyl lactate contributes cream and nut flavors. This compound is produced by malo-lactic fermentation [2]; therefore malo-lactic fermentation may be occurring in the wine as well.

\subsection{Higher Alcohols}

Higher major alcohols were the most abundant volatiles in all the studied wines. They are formed mainly during the first two stages of alcoholic fermentation [3,21]. In our work, 25 higher alcohols were identified and quanti fied, forming the largest group of volatile compounds. Their concentrations varied from 248 to $886 \mathrm{mg} / \mathrm{L}$ and 
Table 2. Concentrations and OAVs of volatile compounds in cabernet sauvignon wines from Changli County.

\begin{tabular}{|c|c|c|c|c|c|c|c|c|}
\hline \multirow{2}{*}{ NO. } & \multirow{2}{*}{ RT } & \multirow{2}{*}{ Compounds } & \multicolumn{3}{|c|}{ Concentration $(\mu \mathrm{g} / \mathrm{L})$} & \multirow{2}{*}{$\begin{array}{l}\text { Odor threshold } \\
\qquad(\mu \mathrm{g} / \mathrm{L})\end{array}$} & \multirow{2}{*}{$\mathrm{OAV}^{\mathrm{b}}$} & \multirow{2}{*}{ Odor description } \\
\hline & & & Max. & Min. & Mean & & & \\
\hline 1 & 3.26 & ethyl acetate & 90000 & 11700 & 42600 & $7500[1]$ & $>1$ & fruity, sweet \\
\hline 2 & 5.60 & isobutyl acetate & 180 & 70 & 80 & $1600[15]$ & 0.1 & strawberry, fruity, flowery \\
\hline 3 & 6.15 & ethyl butyrate & 1900 & 500 & 800 & $20[16]$ & $>1$ & sour fruit, strawberry, fruity \\
\hline 4 & 6.54 & 1-propanol & 20400 & 5800 & 10300 & $50000[2]$ & $0.1-0.5$ & fresh, alcohol \\
\hline 5 & 6.96 & ethyl isovalerate & 80 & 20 & 30 & $3[8]$ & $>1$ & banana, sweet fruity \\
\hline 6 & 8.14 & isobutyl alcohol & 105200 & 31000 & 52900 & $40000[16]$ & $>1$ & fusel, alcohol \\
\hline 7 & 8.36 & isopentyl acetate & 2800 & 200 & 600 & $30[16]$ & $>1$ & fresh, banana \\
\hline 8 & 9.66 & 1-butanol & 4700 & 1600 & 2800 & $150000[16]$ & $<0.1$ & medicinal, alcohol \\
\hline 9 & 11.59 & isopentyl alcohol & 567500 & 164400 & 328100 & $30000[16]$ & $>1$ & alcohol, harsh, bitter \\
\hline 10 & 12.03 & ethyl hexanoate & 1300 & 400 & 700 & $14[16]$ & $>1$ & green apple, fruity, strawberry, anise \\
\hline 11 & 12.83 & 3-methyl-3-buten-1-ol & 300 & 100 & 200 & $600[*]$ & $0.1-0.5$ & light fruity, sweet fruity $[8]$ \\
\hline 12 & 12.94 & 1-pentyl alcohol & 400 & 200 & 300 & $80000[2]$ & $<0.1$ & alcohol \\
\hline 13 & 13.34 & hexyl acetate & 20 & 10 & 10 & $1500[16]$ & $<0.1$ & pleasant fruity, pear \\
\hline 14 & 13.84 & 2-O-2-phenylethyl formate & 2600 & 60 & 600 & n.d. & & \\
\hline 15 & 14.99 & isohexyl alcohol & 600 & 200 & 400 & $5000[*]$ & 0.5 & tropical fruity, light fruity \\
\hline 16 & 15.20 & 2-heptanol & 40 & 10 & 20 & $200-300[*]$ & $0.1-0.5$ & lemon, orange, copper[8] \\
\hline 17 & 15.40 & 3-methyl-1-pentanol & 900 & 200 & 500 & $500[*]$ & 1 & soil, mushroom \\
\hline 18 & 15.80 & ethyl lactate & 237400 & 43300 & 100100 & $14000[2]$ & $>1$ & lactic, raspberry \\
\hline 19 & 1392 & 1-hexanol & 28400 & 11400 & 17300 & $8000[16]$ & $>1$ & green, grass \\
\hline 20 & 16.56 & (E)-3-hexen-1-ol & 2100 & 600 & 1000 & $400[17]$ & $>1$ & Green grass, herb[8] \\
\hline 21 & 16.95 & 3-ethoxy-1-propanol & 600 & 100 & 70 & $100[20]$ & $0.5-1$ & \\
\hline 22 & 17.20 & (Z)-3-hexen-1-ol & 1500 & 700 & 900 & $400[17]$ & $>1$ & Green grass, herb[8] \\
\hline 23 & 17.93 & (E)-2-hexen-1-ol & 800 & 150 & 300 & $400[17]$ & $0.5-1$ & Green grass, herb[8] \\
\hline 24 & 18.23 & (Z)-2-hexen-1-ol & 370 & 100 & 110 & $400[17]$ & $0.1-0.5$ & Green grass, herb[8] \\
\hline 25 & 18.43 & $\begin{array}{l}\text { ethyl 2-hydroxy } \\
\text {-3-methyl butyrate }\end{array}$ & 50 & 10 & 30 & $1000[19]$ & $<0.1$ & Pineapple, strawberry, tea, honey[8] \\
\hline 26 & 18.69 & ethyl octanoate & 740 & 130 & 400 & $5[16]$ & $>1$ & pineapple, pear, floral \\
\hline 27 & 19.51 & 1-heptanol & 260 & 40 & 100 & $200-300[*]$ & $0.1-0.5$ & lemon, orange, copper[8] \\
\hline 28 & 19.87 & linalool oxide & 50 & 10 & 10 & $500[19]$ & $<0.1$ & rose, wood $[8]$ \\
\hline 29 & 20.58 & 2-ethyl hexanol & 80 & 30 & 40 & $8000[*]$ & $<0.1$ & mushroom, sweet fruity[8] \\
\hline 30 & 21.17 & isooctanol & 400 & 60 & 150 & $900[2]$ & $0.1-0.5$ & fatty, orange, rose \\
\hline 31 & 21.39 & $\beta$-ionone & 9 & 1 & 4 & $0.09[17]$ & $>1$ & raspberry, violet, sweet fruity \\
\hline 32 & 21.48 & a -ionone & 6 & 2 & 3 & $0.09[17]$ & $>1$ & raspberry, violet, sweet fruity \\
\hline 33 & 22.14 & $\begin{array}{l}\text { ethyl 2-hydroxy } \\
\text {-4-methyl valerate }\end{array}$ & 80 & 10 & 40 & n.d. & & \\
\hline 34 & 22.30 & linalool & 130 & 10 & 40 & $25[15]$ & $>1$ & muscat, flowery, fruity \\
\hline 35 & 22.67 & 1-octanol & 230 & 70 & 140 & $900[2]$ & $0.5-0.1$ & flesh orange, rose, sweet herb \\
\hline
\end{tabular}




\begin{tabular}{|c|c|c|c|c|c|c|c|c|}
\hline \multirow{2}{*}{ NO. } & \multirow{2}{*}{ RT } & \multirow{2}{*}{ Compounds } & \multicolumn{3}{|c|}{ Concentration $(\mu \mathrm{g} / \mathrm{L})$} & \multirow{2}{*}{$\begin{array}{l}\text { Odor threshold }{ }^{\mathrm{a}} \\
\qquad(\mu \mathrm{g} / \mathrm{L})\end{array}$} & \multirow{2}{*}{$\mathrm{OAV}^{\mathrm{b}}$} & \multirow{2}{*}{ Odor description } \\
\hline & & & Max. & Min. & Mean & & & \\
\hline 36 & 22.89 & isopentyl lactate & 740 & 170 & 300 & $200[*]$ & $>1$ & cream, nut[4] \\
\hline 37 & 23.08 & isobutyric acid & 200 & 40 & 60 & $8100[14]$ & $<0.1$ & phenol, chemical, fatty \\
\hline 38 & 23.25 & 2,3-butanediol & 8600 & 800 & 3200 & $120000[2,18]$ & $<0.1$ & butter, creamy \\
\hline 39 & 23.83 & 4-terpineol & 110 & 10 & 20 & $110-400[13]$ & $0.1-0.5$ & light aroma, wood, soil[8] \\
\hline 40 & 24.29 & $2(3 \mathrm{H})$-dihydro-furanone & 900 & 100 & 300 & $50000[15]$ & $<0.1$ & milk, cream[8] \\
\hline 41 & 24.91 & ethyl decanoate & 100 & 4 & 30 & $200[20]$ & $0.1-0.5$ & fruity, fatty, pleasant \\
\hline 42 & 25.49 & isopentyl octanoate & 240 & 40 & 90 & $125[2]$ & $0.5-1$ & sweet, light fruity, cheese, cream \\
\hline 43 & 25.67 & 1-nonanol & 110 & 30 & 40 & $600[*]$ & $0.1-0.5$ & $\begin{array}{l}\text { apple, banana, raspberry, strawberry, } \\
\text { rose }[8]\end{array}$ \\
\hline 44 & 25.98 & diethyl succinate & 52800 & 4800 & 23100 & $200000[16]$ & $0.1-0.5$ & light fruity \\
\hline 45 & 26.40 & ethyl 9-decenoate & 5 & 1 & 1 & $100[*]$ & $<0.1$ & light fruity, fatty[8] \\
\hline 46 & 26.62 & $\beta$ - terpineol & 200 & 20 & 80 & $110-400[13]$ & $0.1-0.5$ & wood, soil [8] \\
\hline 47 & 27.10 & 3-methoil-1-propanol & 120 & 60 & 70 & $1000[15]$ & 0.1 & raw potato, garlic \\
\hline 48 & 28.53 & 1-decanol & 150 & 20 & 60 & $400[2]$ & $0.1-0.5$ & orange flowery, special fatty \\
\hline 49 & 29.71 & phenethyl acetate & 500 & 80 & 170 & $250[16]$ & $0.5-1$ & pleasant, floral \\
\hline 50 & 29.86 & $\beta$-damascenone & 20 & 3 & 7 & $0.05[16]$ & $>1$ & $\begin{array}{l}\text { bark, canned peach, baked apple, dry } \\
\text { plum }\end{array}$ \\
\hline 51 & 30.60 & ethyl laurate & 40 & 0 & 5 & $1500[*]$ & $<0.1$ & sweet, floral, fruity, cream \\
\hline 52 & 30.91 & hexanoic acid & 1700 & 100 & 900 & $420[16]$ & $>1$ & cheese, rancid \\
\hline 53 & 31.34 & benzyl alcohol & 2000 & 500 & 900 & $200000[15]$ & $<0.1$ & almond \\
\hline 54 & 32.15 & 2-phenyl-ethanol & 140100 & 30800 & 71700 & $14000[16]$ & $>1$ & flowery, pollen, perfume \\
\hline 55 & 32.99 & $\begin{array}{l}\text { 5-butyl-dihydro-4-methyl } \\
-2(3 \mathrm{H}) \text {-furanone }\end{array}$ & 1350 & 80 & 170 & $67[2]$ & $>1$ & peach, coco \\
\hline 56 & 33.44 & dodecan-1-ol & 40 & 0 & 10 & $1000[2]$ & $<0.1$ & $\begin{array}{l}\text { unpleasant in higher concentration, } \\
\text { flowery in low concentration }\end{array}$ \\
\hline 57 & 34.48 & $\begin{array}{l}\text { p-ethyl-2-methoxy phe- } \\
\text { nol }\end{array}$ & 10 & 0 & 1 & $33[16]$ & 0.1 & medicine, wood, clove, smoky \\
\hline 58 & 34.76 & {$[E]$-nerolidol } & 200 & 10 & 30 & $700[*]$ & $0.1-0.5$ & wood, orange, light fruity \\
\hline 59 & 34.90 & ethyl myristate & 10 & 0 & 1 & $2000[*]$ & $<0.1$ & sweet fruity, butter, fatty odor[8] \\
\hline 60 & 35.24 & octanoic acid & 10000 & 700 & 3400 & $500[16]$ & $>1$ & rancid, harsh, cheese, fatty acid \\
\hline 61 & 36.77 & eugenol & 6 & 1 & 1 & $6[2,17]$ & $0.1-0.5$ & smoky, clove \\
\hline 62 & 36.94 & p-ethyl phenol & 24 & 2 & 8 & $440[15]$ & $<0.1$ & phenolic, leather, spicy, almond \\
\hline 63 & 38.15 & ethyl hexadecanoate & 24 & 0 & 2 & $1500[2,18]$ & $<0.1$ & fatty, rancid, fruity, sweet \\
\hline 64 & 38.59 & n-decanoic acid & 730 & 10 & 140 & $1000[16]$ & $0.1-0.5$ & fatty, unpleasant \\
\hline 65 & 38.94 & 2,4-di-tert-butyl-phenol & 370 & 60 & 150 & $200[2,17]$ & $0.5-1$ & phenolic \\
\hline
\end{tabular}

(a) The reference from which the odor threshold and odor description have been taken is given in parentheses. [1] Guth (1997b). The matrix was a 10\% water/ethanol solution; [2] and [19] $\mathrm{Li}$ (2006) and Sun et al. (2004). The matrix was a $12 \%$ ethanol/water mixture containing $5 \mathrm{~g} / \mathrm{L}$ tartaric acid at $\mathrm{pH}$ 3.2. [8,15-18] Ferreira et al. (2000), Aznar et al. (2003), Cullere et al. (2004), Gomez et al. (2007) and Lopez et al. (2004). The matrix was an 11\% water/ethanol solution containing $7 \mathrm{~g} / \mathrm{l}$ glycerol and $5 \mathrm{~g} / 1$ tartaric acid, with the $\mathrm{pH}$ adjusted to 3.4 with $1 \mathrm{M} \mathrm{NaOH}$; [13] José et al. (2004). The matrix was a $10 \%$ water/ethanol solution containing $5 \mathrm{~g} / 1$ tartaric acid. [20] Peinado, et al. (2004). The matrix was an $11 \%$ water/ethanol solution containing $5 \mathrm{~g} / 1$ tartaric acid, with the $\mathrm{pH}$ adjusted to 3.4 with $1 \mathrm{M} \mathrm{NaOH}$; [*] Calculated in the Laboratory of Wine Olfactometry, College of Enology, Northwest A \& F University, China. Orthonasal thresholds were calculated in a $12 \%$ ethanol/water mixture containing $5 \mathrm{~g} / \mathrm{L}$ tartaric acid at pH 3.2. n.d., not detected.

(b) Odor activity value calculated by dividing concentration by the odor threshold value of the compound. 
they made up of about $75 \%$ of the total aromatic compounds. Aromatic compounds with OAVs higher than one were isobutyl alcohol, isopentyl alcohol, 3-methyl-1pentyl alcohol, 1-hexanol, (E,Z)-3-hexen-1-ol and 2phenyl-ethanol. Isobutyl and isopentyl alcohols have fusel characters and may give a bitter or harsh sensory odor when in high concentrations. 3-methyl-1-pentyl alcohol has soil and mushroom nuances. 1-hexanol and hexen-1-ol contribute green grass, herb odor. 2-phenylethanol gives flowery, pollen, and perfume nuances.

\subsection{Fatty Acids}

Four fatty acids were detected in the sample wines. Their concentrations ranged from 0.816 to $12.63 \mathrm{mg} / \mathrm{L}$ and accounted for $0.26-0.98 \%$ of the total volatile compounds. The OAVs of hexanoic and octanoic acids were higher than one. They contributed cheese and cream flavors in lower concentrations, while giving a rancid and harsh odor in higher concentration. Although the presence of $\mathrm{C}_{6}-\mathrm{C}_{10}$ fatty acids is usually related to the occurrence of negative odors, they are very important for aromatic equilibrium in wines because they oppose the hydrolysis of the corresponding esters [22].

\subsection{Terpenols}

Numerous studies have reported that the terpenoid compounds could be used analytically for varietal characterization. Terpene compounds belong to the secondary plant constituents, of which biosynthesis begins with acetyl-coenzyme A (CoA). Terpenes are not changed by yeast metabolism during fermentation [20]. Five terpenes were detected in sample wines: linalool, linalool oxide, 4-terpineol, $\beta$-terpineol and $[E]$-nerolidol. Only linalool had an OAV greater than one and contributed muscat, flowery and fruity odors. Because they have overlapping effects, terpenols may play an important role in contributing to the overall aroma.

\subsection{Norisoprenoids}

In this chemical group, $\alpha$-ionol, $\beta$-ionol, and $\beta$-damascenone, three norisoprenoids often reported, were all detected in sample wines, and all had odor activity. The ionols are responsible for the raspberry, violet and sweet fruity nuances, while $\beta$-damascenone contributes odors of bark, canned peach, baked apple, and dry plum.

\subsection{Volatile Phenols}

Some volatile phenols, such as eugenol and guaiacol, may be the major differences between Cabernet Sauvignon and other red variety wines [8]. Four phenols were identified in our study, but all seemed to have no odor contribution. Eugenol and 2,4-di-tert-butyl phenol have OAVs between 0.5 to 1 . Eugenol has smoky and clove odors. 2,4-di-tert-butyl phenol gives phenols' chemical character.

\subsection{Others}

An AEDA study regarding the odorants of Bordeaux Cabernet Sauvignon red wines showed that 3-methiol1-propanol, furaneol and homofuraneol had high flavor dilution (FD) factors [6]. In our work, two furans and one sulfur compound were detected in the sample wines: 2(3H)-dihydrofuran, 5-butyl-dihydro-4-methyl-2(3H)furan and 3-methiol-1-propanol. Only 5-butyl-dihydro4-methyl-2(3H)-furan had odor activity and smelled of peach and cocoa.

\section{CONCLUSIONS}

Aroma compounds in Cabernet Sauvignon dry red wine from Changli County were evaluated by SPME-GC-MS; 65 volatile compounds were identified and quantified. Their concentrations ranged from $0.5 \mu \mathrm{g} / \mathrm{L}$ to $2.23 \mathrm{~g} / \mathrm{L}$. Twenty-one volatile compounds were considered to be the powerful impact odorants of this wine because their OAVs were more than one. These active volatile compounds include eight esters, seven higher alcohols, two fatty acids, one terpenols (linalool), $\alpha / \beta$-ionol and $\beta$-damascenone, one compound of furan. These compounds have different sensory characters and give the wine very complicated aroma, which included not only pleasant floral and fruity odors, but also cheese, clove flavors, and grassy and smoky aromas. Taste or olfactory experiments could be designed to confirm the sensory characteristics of the wine.

\section{ACKNOWLEDGEMENTS}

This project was supported by the China National Science Fund (30571281). The authors are grateful to the Huaxia Winemaking Company and the Yueqiannian Winemaking Company (Changli County) for supplying the samples used in this study.

\section{REFERENCES}

[1] H. Guth, (1997) Quantiation and sensory studies of character impact odorants of different white wine varieties. Journal of Agriculture and Food Chemistry, 45, 3027-3032.

[2] H. Li, (2006) Wine Tasting. Beijing, China: China Science Press 29-106.

[3] R. Perestrelo, A. Fernandes, F. F. Albuquerque, J. C. Marques, and J. S. Camara, (2006) Analytical characterization of the aroma of Tinta Negra Mole red wine: Identification of the main odorants compounds. Analytica Chimica Acta, 563, 154-164.

[4] H. Li, Y. S.Tao, W. H. Kang, and C. L. Yin, (2006) Wine aroma analytical investigation progress on GC (Review). Journal of Food Science and Biotechnology (China), 25, 99-104.

[5] M. Vilanova, and C. Martinez, (2007) First study of determination of aromatic compounds of red wine from Vitis vinifera CV, Castanal grown in Galicia (NW Spain). Euro- 
pean Food Research and Technology, 224, 431-436.

[6] Y. Kotseridis and R. Baumes, (2000) Identification of impact odorants in Bordeaux red grape juice, in the commercial yeast used for its fermentation, and in the produced wine. Journal of Agriculture and Food Chemistry, 48, 400-406.

[7] R. Lopez, V. Ferreira, P. Hernamdez, and J. F. Cacho, (1999) Identification of impact odorants of young red wines made with Merlot, Cabernet Sauvignon and Grenache grape varieties: A comparative study. Journal of the Science of Food and Agriculture, 79, 1461-1467.

[8] V. Ferreira, R. Lopez, and J. F. Cacho, (2000) Quantitative determination of the odorants of young red wines from different grape varieties. Journal of the Science of Food and Agriculture, 80, 1659-1667.

[9] M. Zhang, Q. Xu, C. Duan, and Y. Wu, (2007) Comparative study of aromatic compounds in young red wines from Cabernet Sauvignon, Cabernet Franc, and Cabernet Gernischet varieties in China. Journal of Food Science, 72(5), c248-c252.

[10] Y. S. Tao, H. Li, and H. Wang, (2007) Optimization of wine aroma analysis by solid-phase microextraction. Journal of Northwest A \& F University: Natural Science Edition, 35(12), 181-185.

[11] O. I. V. (1990) Recueil des methods internationals d'analyse des vins et des mouts. Paris: Office International de la Vigne et du Vin.

[12] V. Ferreira, R. Lopez, A. Escudero, and J. F Cacho, (1998) Quantitative-determination of trace and ultra-trace flavor active compounds in red wines through Gas-Chromatographic Ion-Trap Mass-Spectrometric analysis of micro-extracts, Journal of Chromatography A, 806, 349-354.

[13] M. O. José, M. A. Isabel, M. P. Óscar, S. M. José, and J. A. António, (2004) Characterization and differentiation of five "Vinhos Verdes" grape varieties on the basis of monoterpenic compounds. Analytica Chimica Acta, 513(1), 269-275.

[14] H. Li , Y. S. Tao, H. Wang, and L. Zhang, (2008) Impact odorants of Chardonnay dry white wine from Changli County (China). European Food Research and Technology, 227(1), 287-292.

[15] M. Aznar, R. Lopez, J. Cacho, and V. Ferreira, (2003) Prediction of aged red wine aroma properties from aroma chemical composition, Partial least squares regression models. Journal of Agriculture and Food Chemistry, 51, 2700-2707.

[16] L. Cullere, A. Escudero, J. Cacho, and V. Ferreira, (2004) Gas chromatograpgy-Olfactory and chemical qualitative study of the aroma of six premium quality Spanish aged red wines. Journal of Agriculture and Food Chemistry, 52, 1653-1660.

[17] M. J. Gomez, J. F. Cacho, V. Ferreira, I. M. Vicario, and F. J. Heredia, (2007) Volatile components of Zalema white wines. Food Chemistry, 100, 1464-1473.

[18] R. Lopez, E. Ezpeleta, I. Sanchez, J. Cacho, and V. Ferreira, (2004) Analysis of the aroma intensities of volatile compounds released from mild acid hydrolysates of odorless precursors extracted from Tempranillo and Grenache grapes using gas chromatography-olfactometry. Food Chemistry, 88, 95-103.

[19] B. G. Sun and Y. P. Liu, (2004) Food Spice and Flavor Handbook, China Petroleum Press.

[20] R. A. Peinado, J. Moreno, M. Medina, and J. C. Mauricio, (2004) Changes in volatile compounds and aromatic series in sherry wine with high gluconic acid levels subjected to aging by submerged flor yeast cultures. Biotechnology Letters, 26(9), 757-762.

[21] M. Gil, J. M. Cabellos, T. Arroyo, and M. Prodanov, (2006) Characterization of the volatile fraction of young wines from the Denomination of Origin "Vinos de Madrid" (Spain). Analytica Chimica Acta, 563, 145-153.

[22] A. Bertrand, (1981) Formation des substances volatiles au cours de la fermentation alcoolique, Incidence sur la qualit'e du vin. Colloque Soc. Fr. Microbiol., Reims, 252-267. 